\title{
An Extended Physical Map of the TOX2 Locus of Cochliobolus carbonum Required for Biosynthesis of HC-T oxin
}

\author{
J oong-Hoon Ahn,* Y i-Qiang Cheng, $\boldsymbol{\dagger}$ and J onathan D. Walton ${ }^{, 1}$ \\ *Department of Forest Resources, Konkuk University, S eoul 143-701, Korea; $†$ School of Pharmacy, University \\ of Wisconsin, Madison, Wisconsin 53705; and $\ddagger$ Department of Energy Plant Research Lab, \\ Michigan State University, East Lansing, Michigan 48824
}

Accepted for publication September 28, 2001

Ahn, J.-H., Cheng, Y.-Q., and Walton, J. D. 2002. An extended physical map of the TOX2 locus of Cochliobolus carbonum required for biosynthesis of $\mathrm{HC}$ toxin. Fungal Genetics and Biology 35, 31-38. In genetic crosses, $\mathrm{HC}$-toxin production in the filamentous fungus Cochliobolus carbonum appears to be controlled by a single locus, TOX2. At the molecular level, TOX2 is composed of at least seven duplicated and coregulated genes involved in $\mathrm{HC}$-toxin biosynthesis, export, and regulation. All copies of four of the TOX2 genes were previously mapped within a $540-\mathrm{kb}$ stretch of DNA in strain SB111. Subsequently, an additional three TOX2 genes, TO XE, TO XF, and TOXG, have been discovered. In this paper we have mapped all copies of the new genes, a total of seven, and show that except for one of the two copies of TOXE, which was previously shown to be on a chromosome of $0.7 \mathrm{Mb}$ in strain SB111, they are all linked to the previously known TOX2 genes within $\sim 600 \mathrm{~kb}$ of each other on a chromosome of $3.5 \mathrm{Mb}$. We show here that this chromosome also contains at least one non-TO X2 gene, EXG2, which encodes an exo- $\boldsymbol{\beta} 1,3$-glucanase. EXG 2 is still present in strains that have undergone spontaneous deletion of up to $\sim 1.4 \mathrm{M} \mathrm{b}$ of the $3.5-\mathrm{M} \mathrm{b}$ chromosome. The results contribute to our understanding of the complex organization of the genes involved in $\mathrm{HC}$ toxin biosynthesis and are consistent with the hypoth-

\footnotetext{
${ }^{1}$ To whom correspondence should be addressed. F ax: (517) 353-9168. E-mail: walton@msu.edu.
}

esis that a reciprocal chromosomal translocation accounts for the pattern of distribution of the TOX2 genes in different $C$. carbonum isolates.

(c) 2002 Elsevier Science (USA)

Index Descriptors: cyclic peptide; gene cluster; hostselective toxin; plant pathogenesis.

Filamentous fungi produce a variety of secondary metabolites of medical, industrial, and ecological importance. Examples include penicillin, cyclosporin, ergot alkaloids, aflatoxins, and amatoxins. E cologically, secondary metabolites are important virulence and specificity factors for many plant pathogenic fungi, especially those in the genera Alternaria and Cochliobolus (Kohmoto and Otani, 1991; Walton, 1996).

$M$ any of the genes involved in fungal secondary metabolism share certain characteristic features, such as clustering, absence even from closely related nonproducing isolates, and association with chromosomal rearrangements or dispensable (supernumerary) chromosomes (Keller and H ohn, 1997; Walton, 2000). F or example, 25 genes involved in sterigmatocystin biosynthesis are clustered within $60 \mathrm{~kb}$ in Aspergillus nidulans (Brown et al., 1996), and 3 penicillin biosynthetic genes are clustered in Penicillium chrysogenum and Aspergillus nidulans (D iez et al., 1990; M acCabe et al., 1990). T-toxin production in Cochliobolus heter ostr ophus requires 2 genes that, because of a translocation, are genetically but not physically linked, and both genes are absent from closely related isolates that do 
not make T-toxin (Kodama et al., 1999). Genes required for AK-toxin in Alternaria alternata J apanese pear pathotype are physically linked and absent from other species of A. alternata (Tanaka and Tsuge, 2000).

Other genes that control fungal virulence but that are not known to be associated with secondary metabolism have also been shown to have one or more of these characteristics. A set of genes required for virulence, including PDA1 encoding pisatin demethylase, are clustered on a dispensable chromosome in Nectria haematococca M P VI (H an et al., 2001; Covert, 1998). Some isolates of Cladosporium fulvum pathogenic on tomato containing Cf9 lack the avr9 gene (van Kan et al., 1991). The telomere-localized avirulence gene AVR-Pita in Magnaporthe grisea is unstable, resulting in its complete absence in many virulent isolates (O rbach et al., 2000). The gene for NIP1, a race-specific peptide elicitor from the barley pathogen Rhynchosporium secalis, is absent in most virulent isolates (Rohe et al., 1995). A chromosome in Colletotrichum gloeosporioides affecting host range is dispensable and transferable (He et al., 1998).

Race $1\left(\mathrm{ToX2}^{+}\right)$isolates of the maize pathogen Cochliobolus (Helminthosporium) carbonum race 1 produce the host-selective toxin, $\mathrm{HC}$-toxin, of structure cyclo(DPro-L-Ala-D -Ala-L-Aeo), where Aeo stands for 2-amino9,10-epoxi-8-oxodecanoic acid. Mendelian and molecular genetic analyses of the pathogen and the host indicate that $\mathrm{HC}$-toxin is a critical virulence and specificity factor in the interaction between maize and $\mathrm{C}$. carbonum (Walton, 1996).

In genetic crosses, production of $\mathrm{HC}$-toxin appears to be controlled by a single locus, TOX2 (Scheffer et al., 1967). At the molecular level, TOX2 is a complex locus composed of at least seven genes with an established or probable role in $\mathrm{HC}$-toxin biosynthesis, export, and regulation. All of these genes are present in two or three copies in all naturally occurring toxin-producing $\left(\mathrm{Tox}^{+}\right)$isolates of $C$. carbonum, and all are absent from natural toxin nonproducing ( $\mathrm{Tox}^{-}$) isolates. Unlike some of the copies of the ACR-toxin biosynthetic genes in A. alternata (Tanaka and Tsuge, 2000), all of the copies of the known TOX2 genes appear to be functional. This conclusion is based on the fact that Tox2 ${ }^{-}$strains have never been recovered by disrupting fewer than all of the copies of any particular TOX2 gene. H owever, because not all copies of some of the TOX2 genes have been disrupted in all combinations, it is possible that some of them are nonfunctional.

There are seven known genes within TOX2. HTS1 encodes a 570-kD a nonribosomal peptide synthetase, TOXA encodes a putative HC-toxin efflux carrier, TOXC encodes a fatty acid synthase beta subunit, TOXD encodes a putative dehydrogenase (with no role yet established in $\mathrm{HC}$ toxin biosynthesis), TOXE encodes a pathway-specific transcription factor, TOXF encodes a putative branchedchain amino acid transaminase, and TOXG encodes an alanine racemase (Panaccione et al., 1992; Pitkin et al., 1996; Ahn and Walton, 1996, 1997, 1998; Cheng et al., 1999; Cheng and Walton, 2000).

In some isolates, including the laboratory strain SB111, all copies of HTS1, TOXA, TOXC, and TOXD are located within a 540-kb region on the largest (3.5- $\mathrm{M} \mathrm{b}$ ) chromosome (Ahn and Walton, 1996, 1998; Canada and D unkle, 1997). One copy of TOXE was later shown to be somewhere on this same chromosome, with the other copy on a chromosome of $0.7 \mathrm{M} \mathrm{b}$ (Ahn and Walton, 1998). We call this particular pattern of TOX2 gene distribution Type 1 . In contrast, in other isolates, typified by isolate 151 and called Type 2, all of the TOX2 genes, including both copies of TOXE, are on a chromosome of $2.2 \mathrm{Mb}$ (Ahn and Walton, 1996, 1998; Canada and D unkle, 1997).

The TOX2 locus of $C$. carbonum is genetically unstable. $M$ ajor deletions in the TOX2 region occur in $\sim 5 \%$ of random ascospore progeny (Pitkin et al., 2000). Some of the deletion strains lack $\sim 1.4 \mathrm{M} \mathrm{b}$ of the $3.5-\mathrm{M} \mathrm{b}$ chromosome yet show as their only phenotype a reduction in virulence. Thus, it appears that a large portion of the 3.5-M b chromosome is dispensable (Pitkin et al., 2000). It is unknown whether the entire chromosome is dispensable because all of the deletion strains retain at least $\sim 1.9 \mathrm{M} \mathrm{b}$ of the 3.5-M b chromosome. Furthermore, there is evidence that this chromosome contains expressed singlecopy genes common to $\mathrm{Tox2}^{+}$and $\mathrm{To}_{\mathrm{O}} \mathrm{2}^{-}$isolates that are not involved in toxin biosynthesis and might have housekeeping functions (Cheng et al., 1999). M apping studies with the TOX2 genes and with other probes led to the hypothesis that the 3.5- and 0.7-M b chromosomes (Type 1) are related to the 2.2-M b chromosome (Type 2) by a reciprocal translocation (Ahn and Walton, 1996, 1998). The translocation partner of the 2.2-M b chromosome in Type 2 isolates was postulated to be a chromosome of 2.0 $\mathrm{M} \mathrm{b}$. To date, this chromosome has been found to contain only genes common to $\mathrm{Tox2}^{+}$and $\mathrm{Tox2}^{-}$isolates.

Since the original mapping studies (Ahn and Walton, 1996), three additional TOX2 genes (TOXE, TOXF, and TOXG ) have been characterized. TOXE is present in two copies in all Tox2 ${ }^{+}$isolates, and in isolates with a 3.5-M b TOX2 chromosome one copy was shown to be somewhere on this chromosome (Ahn and Walton, 1998). TOXF and TOXG are tightly and divergently clustered, their tran- 
scriptional start sites being separated by $195 \mathrm{bp}$. M ost $\mathrm{ToX2}^{+}$isolates contain three copies of the TOXF/G cluster (Cheng et al., 1999; Cheng and Walton, 2000). Because TOXF and TOXG were identified by their presence on the same bacterial artificial chromosome (BAC) as one copy of TOXD, at least one copy of TOXF/G must be physically linked to the other TOX2 genes (Cheng et al., 1999), but otherwise their locations have not been established.

To understand the structure of the TOX2 locus more completely, we have now physically mapped TOXE, TOXF, and TOXG relative to the other TOX2 genes in isolate SB111 of $C$. carbonum. The results shed light on the evolutionary history of this complex locus and support the hypothesis that a reciprocal translocation has affected the chromosomal distribution of the TOX2 genes since the origin of $\mathrm{HC}$-toxin biosynthesis in $\mathrm{C}$. carbonum.

\section{MATERIALS AND METHODS}

C. carbonum strain SB111 (race $1 ; \mathrm{TOX2}^{+} ; \mathrm{ATCC}$ 90305) was stored as a spore suspension in $25 \%$ (v/v) glycerol at $-80^{\circ} \mathrm{C}$ and routinely grown on V8-juice agar plates. Wild-type $\mathrm{C}$. carbonum Tox2 ${ }^{+}$isolates such as 151 were obtained from L. D unkle, Purdue University (Ahn and Walton, 1996; Canada and D unkle, 1997). D eletion strains are described in Pitkin et al. (2000).

pCB 1004 (Carroll et al., 1994) containing the gene encoding hygromycin phosphotransferase driven by the $\operatorname{trpC}$ promoter of A. nidulans was digested with Smal, dephosphorylated, and ligated with a Pacl linker ( $\mathrm{New}$ E ngland Biolabs). The resulting plasmid was digested with Pstl and ligated with a 2.9-kb Pstl fragment containing fragments of TOXG and TOXF (Cheng et al., 1999). This plasmid (AJ62) was linearized with B brPI before transformation. Protoplast isolation and fungal transformation were done as described (Scott-Craig et al., 1990; Apel et al., 1993). Transformants were selected for their ability to grow in the presence of hygromycin $(100 \mu \mathrm{g} / \mathrm{ml})$ and purified to nuclear homogenity by two rounds of singlespore isolation.

C. carbonum genomic DNA was isolated as described by Pitkin et al. (1996). The genomic lambda library has been described (Panaccione et al., 1992). The B AC library, described by Cheng et al. (1999), was transferred from 96-well microtiter plates to nylon membranes (ZetaProbe; Bio-Rad) and screened with a 2.9-kb Pstl fragment containing TOXF/G. The TOXE fragment used as probe was a 1-kb EcoRI/E coRI fragment (Ahn and Walton, 1998).
D N A blotting and hybridization followed standard protocols (Sambrook et al., 1989).

The alkaline lysis method (Sambrook et al., 1989) was used to isolate BAC DNA. BAC DNA was digested with Ascl and fractionated by pulsed-field gel electrophoresis (PF GE ) using a CHEF II system (Bio-Rad). Conditions were $1 \%$ agarose, $170 \mathrm{~V}$, with a 0.5 - to 2-s switching interval over $22 \mathrm{~h}$.

Restriction enzyme digestion of agarose-embedded chromosomal DNA was performed as described with some modifications (Ahn and Walton, 1996). The plugs were soaked in restriction enzyme buffer and 20 units of restriction enzyme in Eppendorf tubes, stored overnight on ice, and then incubated at the recommended temperature for $4 \mathrm{~h}$. Conditions for fractionation of large restriction fragments by pulsed-field gel electrophoresis were as previously described (Ahn and Walton, 1996).

\section{RESULTS}

\section{Mapping of TOXE, TOXF, and TOXG}

The location of the copy of TOXE that is on the 3.5-M b TOX2 chromosome in strain SB 111 was determined by chromosome walking. A 40-kb cosmid insert (called cos2), which includes part of HTS1 copy 2 and flanking genomic D N A beyond the $3^{\prime}$ end, was overlapped with a genomic lambda clone insert (called $\lambda E$ ) that contained an endogenous Pacl site and TOXE. The distance from the end of copy 2 of HTS1 to TOXE was estimated to be $\sim 20 \mathrm{~kb}$ based on restriction mapping of $\cos 2$ and $\lambda E$.

The lambda clone was mapped with restriction enzymes, and a 2.0-kb BamH I fragment containing the Pacl site was used to probe a blot of Pacl-digested genomic DNA from C. carbonum SB111. The BamHI fragment hybridized to two fragments of $1 \mathrm{M} \mathrm{b}$ and $20 \mathrm{~kb}$, which are the same sizes as the fragments to which the three copies of TOXC hybridize, and we assume that they are, in fact, the same fragments (Ahn and Walton, 1996). This result indicated that the $20-\mathrm{kb} \mathrm{Pacl}$ fragment containing copy one of TOXC (TOXC-1) abuts the 1-Mb Pacl fragment that contains the two other copies of TOXC.

In $C$. carbonum isolate SB111, the three copies of TOXF/G are present on restriction fragments of different sizes when cut with Apal, Bgll, BstXI, Kpnl, or Pvul. TOXF/G-1, TOXF/G-2, and TOXF/G-3 refer to the copies found on Apal fragments of 18,16 , and $9.6 \mathrm{~kb}$, respectively (Cheng and Walton, 2000). To determine the chro- 


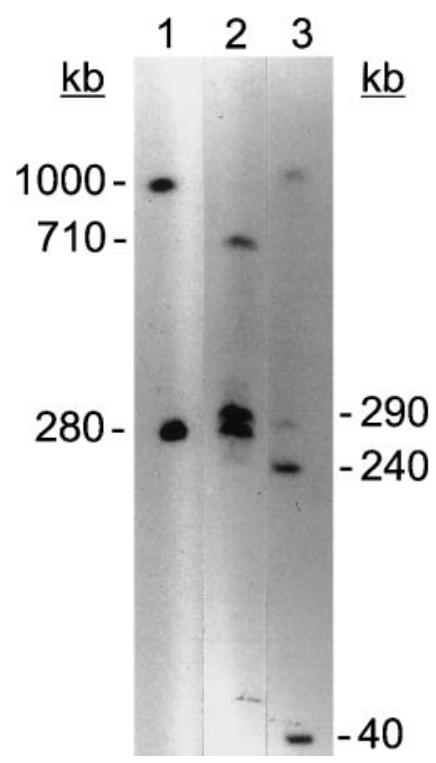

FIG. 1. M apping of TOXF/G by introduction of Pacl sites. Chromosomal D N A was digested with Pacl, fractionated by PF GE, blotted, and probed with a TOXG CDNA. Lane 1, C. carbonum wild type (SB111); lane 2, SB 111 transformed with a Pacl site into copy 1 of TOXF/G; lane 3, SB 111 transformed with a Pacl site into copy 3 of TOXF/G.

mosomal location of these three copies, a DNA blot of intact chromosomes from isolate SB 111 was probed with a TOXG CD N A. All copies of TOXG and TOXF were located on the 3.5-M chromosome in those isolates that have HTS1 on this chromosome, and all copies were on a 2.2-M b chromosome in those isolates that have the TOX2 genes on a chromosome of this size (data not shown).

To obtain a physical map of the three copies of TOXG and TOXF on the 3.5-Mb chromosome, chromosomal DNA of strain SB111 was digested with Pacl, the fragments were separated by PFGE, and the gel was blotted and probed with a TOXG CDNA. TOXG hybridized to fragments of $1 \mathrm{M} \mathrm{b}$ and $280 \mathrm{~kb}$ (Fig. 1, lane 1). The 1-M b Pacl fragment was assumed to be the same fragment that contains two copies of HTS1, TOXA, and TOXC and three copies of TOXD (Ahn and Walton, 1996). The 280-kb Pacl fragment that hybridizes to TOXG was not the same size as any of the Pacl fragments that hybridize with any of the other TO X2 genes.

To map the copies of TOXF/G more precisely on the 3.5-M b chromosome, a Pacl site was introduced into each copy of TOXG by homologous transformation. Twelve transformants were isolated and analyzed by DNA blotting. The location of the transforming plasmid was determined by conventional agarose gel electrophoresis after digestion of genomic DNA with Apal, which can distinguish the different copies of TOXF/G. Chromosomal D NA from transformants in which the plasmid containing the $\mathrm{Pacl}$ site had integrated into different copies of TOXG was digested with Pacl, fractionated by PFGE, blotted, and probed with a TOXG CDNA. When a Pacl site was inserted into copy one of TOXF/G (TOXF/G -1), subsequent digestion with $\mathrm{Pacl}$ resulted in disappearance of the 1-M b hybridizing band and appearance of two new bands of 290 and $710 \mathrm{~kb}$ (Fig. 1, lane 2). On the same blot, TOXE hybridized to a 290-kb band, presumed to be the same one (data not shown). Therefore, TOXF/G-1 is $290 \mathrm{~kb}$ away from an endogenous $\mathrm{Pacl}$ site, which places it $\sim 20 \mathrm{~kb}$ from the end of HTS1-1 in the direction of HTS1-2 (Fig. 2). Insertion of a Pacl site into TOXF/G -2 and subsequent digestion of the transformant DNA with Pacl resulted in the generation of TOXG-hybridizing fragments of 370 and $630 \mathrm{~kb}$, and TOXE hybridized to a 370-kb fragment, presumed to be the same one (data not shown). This places TOXF/G-2 between TOXD-1 and TOXD-3 (Fig. 2).

The location of TOXF/G -3 was determined by chromosome walking using the lambda and $B A C$ genomic libraries. The BAC library was screened with a TOXC CDNA, and a $65-\mathrm{kb}$ BAC insert, 24F 11 , that contains copy 1 of TOXC on a $20-\mathrm{kb}$ Pacl fragment, was found. Restriction analysis of this $B A C$ indicated that its two Pacl sites were on $\mathrm{BamH}$ I fragments of 4.0 and $2.0 \mathrm{~kb}$. The $2.0-\mathrm{kb} \mathrm{BamH} \mathrm{I}$ fragment is the same one that is present in $\lambda E$ (see above) and thus contains the $\mathrm{Pacl}$ site that is closest to TOXE. The Pacl site on the $4.0-\mathrm{kb} \mathrm{BamHI}$ fragment represents a Pacl site on the other side of TOXE away from copy 2 of HTS1. This 4.0-kb BamHI fragment hybridized to fragments of 20 and $280 \mathrm{~kb}$ on a blot of total chromosomal D N A digested with Pacl. The 20-kb fragment is assumed to correspond to the Pacl fragment on which TOXC-1 is located, and the 280-kb fragment is assumed to be the same Pacl fragment to which the third copy of TOXF/G hybridized. In summary, the order of $\mathrm{Pacl}$ fragments across the TOX2 region is $1 \mathrm{Mb}, 20 \mathrm{~kb}$, and $280 \mathrm{~kb}$ from left to right (Fig. 2).

The Pacl/BamHI fragment from the $4.0-\mathrm{kb} \mathrm{BamHI}$ fragment that hybridized only with the $280-\mathrm{kb}$ Pacl fragment was cloned and named $\mathrm{pPC} / \mathrm{B}$. The location of copy 3 of TOXF/G (TOXF/G -3) was determined by introducing a Pacl site into this copy. Digestion of the transformant with Pacl and probing of the blot with a TOXG CDNA resulted in hybridization to two fragments of 40 and 240 $\mathrm{kb}$ and to a fragment of $1 \mathrm{M} \mathrm{b}$ representing copies 1 and 2 of TOXF/G (Fig. 1, lane 3). When stripped and reprobed with $\mathrm{pPC} / \mathrm{B}$, only the $40-\mathrm{kb}$ band hybridized. These results 


\section{A TOX2 region}

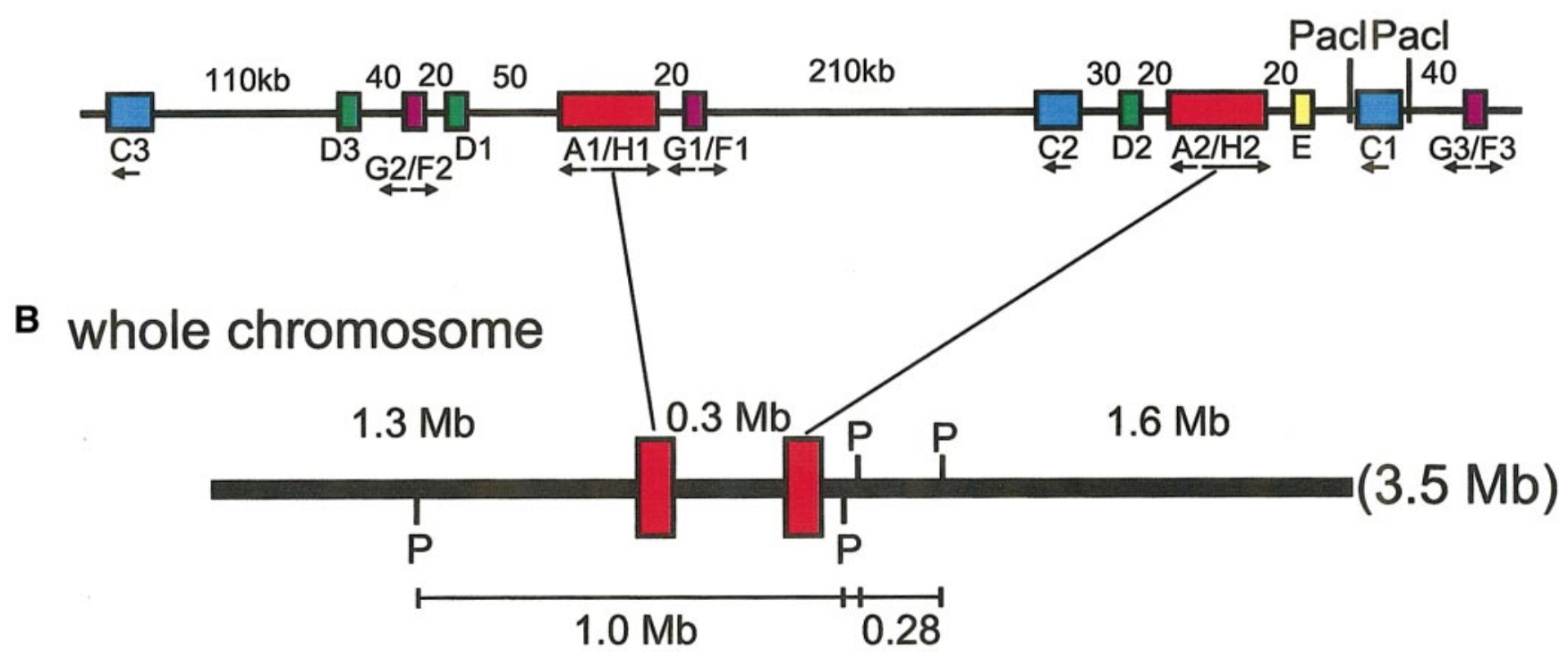

FIG. 2. M ap of the TOX2 locus of $C$. carbonum SB111 (revised from Ahn and Walton, 1996). A/H, the TOXA/HTS1 cluster; C, TOXC; D, TOXD; E, TOXE; F/G, the TOXF/TOXG cluster. Directions of transcription are indicated where known. (A) Local region spanning $\sim 600 \mathrm{~kb}$; distances are in kb. (B) M ap of the entire 3.5-M b chromosome of SB 111; distances are in M b. P stands for native Pacl sites (not all sites on the chromosome are shown). The copies of HTS1 in (A) and (B) are connected by lines. The boxes representing the genes are not drawn to scale.

indicate that TOXF/G -3 is located $\sim 40 \mathrm{~kb}$ from the end of the 20-kb Pacl fragment containing TOXC-1.

The deduced absolute and relative locations of all copies of all known TOX2 genes in isolate SB111, with the exception of one copy of TOXE, is shown in Fig. 2. The other copy of TOXE was earlier shown to be on a $0.7-\mathrm{Mb}$ chromosome in SB 111 and has not been further mapped (Ahn and Walton, 1998). The accuracy of this map (Fig. 2) is limited by the resolution of PFGE and by the assumption that hybridization of two probes to restriction fragments of the same size means that the fragments are the same D N A.

\section{Is the 3.5-Mb TOX2 Chromosome Dispensable?}

Because the TOX2 genes are present only in $\mathrm{T} 0 \times 2^{+}$ isolates and because engineered $\mathrm{Tox}^{-}$mutants are fully viable, the genes necessary for $\mathrm{HC}$-toxin biosynthesis, which to date total $>90 \mathrm{~kb}$ of DNA, are clearly dispensable. It was earlier shown by the analysis of strains with spontaneous deletions of the TO X2 genes in isolate SB 111 that $\sim 1.4 \mathrm{M} \mathrm{b}$ of the 3.5-M b TOX2 chromosome of SB 111 is dispensable (Pitkin et al., 2000). This $1.4-\mathrm{M} \mathrm{b}$ region maps to the left-hand end of the 3.5-M b chromosome as drawn in Fig. 2. H owever, the right-hand end of the TOX2 chromosome is still present in all of the deletion strains described by Pitkin et al. (2000), and therefore this region of the 3.5-M b chromosome might contain essential and dispensable genes. The 3.5-M b chromosome of SB111 does, in fact, contain at least one non-TOX2 gene, EXG2, which encodes an exo- $\beta 1,3$-glucanase (GenBank Accession N o. AF 229446; Kim et al., 2001)(Fig. 3). In Type 2 isolates, in which all of the TOX2 genes are on a 2.2-M b chromosome, EXG 2 is on a 2.0-M b chromosome (data not shown). EXG2 is on a chromosome of $2.0 \mathrm{M} \mathrm{b}$ in Tox ${ }^{-}$ isolates also (data not shown). Because EXG2 is still present in all of the TOX2 deletion strains (Fig. 3) it is on the right-hand end of the 3.5- $\mathrm{Mb}$ chromosome ( $\mathrm{Fig} .2$ ). Insofar as EXG 2 can be considered a housekeeping gene (although it is not a TOX2 gene and is present in all tested C. carbonum isolates, it is dispensable for growth and virulence; $\mathrm{Kim}$ et al., 2001), the 3.5-M b chromosome is thus a composite of housekeeping and dispensable genes.

The deduced chromosomal distribution of all copies of all TOX2 genes and the U-repeat, G242, and EXG2 in Type 1 and Type $2 \mathrm{Tox2}^{+}$isolates of $\mathrm{C}$. carbonum are shown schematically in Fig. 4. The U-repeat and $\mathrm{G} 242$ are 


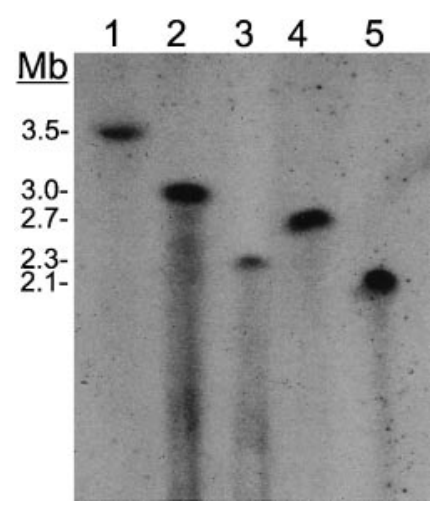

FIG. 3. Sizes of the chromosomes containing EXG2 (Kim et al., 2001) in strains of SB111 with spontaneous deletions in the 3.5-M b TOX2 chromosome. Lane 1, C. carbonum SB 111; lane 2, strain 164R 10; lane 3, strain 512-3; lane 4, strain 543-48; lane 5, 243-7 (Pitkin et al., 2000).

probes that were previously mapped to the chromosomal level (Ahn et al., 1996). The "U-repeat" is a sequence present in subcloned fragment $\mathrm{CC} 62$, which is adjacent to the 3' end of HTS1 (Panaccione et al., 1992). The Urepeat is present in multiple copies in $\mathrm{Tox}^{+}$isolates (see Fig. 1 of Panaccione et al., 1992; J.-H. Ahn and J. D. Walton, unpublished results). The $U$-repeat is absent from Tox2 ${ }^{-}$isolates and is found flanking both copies of HTS1, all three copies of TOXC, and both copies of TOXE in isolate SB111 (Ahn and Walton, 1997, 1998). The Urepeat is on chromosomes of 3.5 and $0.7 \mathrm{Mb}$ in Type 1 isolates and on a chromosome of $2.2 \mathrm{M} \mathrm{b}$ in Type 2 isolates (Ahn and W alton, 1996). G242 is a mapping probe from C. heterostrophus (Tzeng et al., 1992). It was previously shown to be present as a single copy in both $\mathrm{Tox2}^{+}$and Tox2 ${ }^{-}$isolates and to be present on a 3.5-M b chromosome in Type 1 isolates and on a 2.0-M b chromosome in Type 2 isolates (Ahn and Walton, 1996).

\section{DISCUSSION}

All copies of the TOX2 genes had previously been mapped to a region of $\sim 500 \mathrm{~kb}$ on a $3.5-\mathrm{M} \mathrm{b}$ chromosome in isolate SB 111 of C. carbonum (Ahn and Walton, 1996, 1998). H ere we show that, with one exception, all copies of three new genes (TOXE, TOXF, and TOXG) are also part of the same extended gene cluster. The exception is one of the copies of TOXE, which had previously been shown to be on a different chromosome in SB 111 (Ahn and Walton, 1998). H owever, in other isolates both copies of TO XE are also linked to the other TOX2 genes on the same 2.2-M b chromosome (A hn and Walton, 1998). Collectively, these results are consistent with the original genetic studies showing that the trait of $\mathrm{HC}$-toxin biosynthesis appears to be controlled by a single M endelian locus (Scheffer et al., 1967).

The physical organization of the genes for $\mathrm{HC}$-toxin biosynthesis have characteristics that are different from those of other fungal secondary metabolite pathways. Some of the genes are tightly clustered (e.g., HTS1 with TOXA and TOXF with TOXG ) like other fungal secondary metabolite genes, but altogether all copies of the known genes of TOX2 are dispersed over more than $600 \mathrm{~kb}$. There is evidence that some of the genes involved in other fungal secondary metabolite pathways are also dispersed, e.g., TRI 101, which encodes an 0 -acetyltransferase involved in trichothecene biosynthesis in Fusarium species, and at least one of the aflatoxin biosynthetic genes (Kimura et al., 1998; McCormick et al., 1999; Woloshuk and Prieto, 1998). The TOX2 genes are also unusual among fungal secondary metabolite genes in being duplicated or triplicated. The penicillin biosynthetic gene cluster is present in 5 - 14 copies in some strains of Penicillium chrysogenum, but this is probably a result of intensive artificial selection for strain improvement (Fierro et al., 1995). One consequence of the duplication of the TOX2 genes is that the trait of $\mathrm{HC}$-toxin production would be predicted to be quite refractory to loss by mutation. On the other hand, this genetic stability appears to be counteracted, at least in isolates such as SB 111, by the tendency of the 3.5-M b TOX2 chromosome to undergo major deletions (Pitkin et al., 2000).

The results in this paper are consistent with the hypothesis (Ahn and Walton, 1996) that the Type 1 (3.5 M b) and

\section{Type 1 (SB111)}

Type 2 (151)
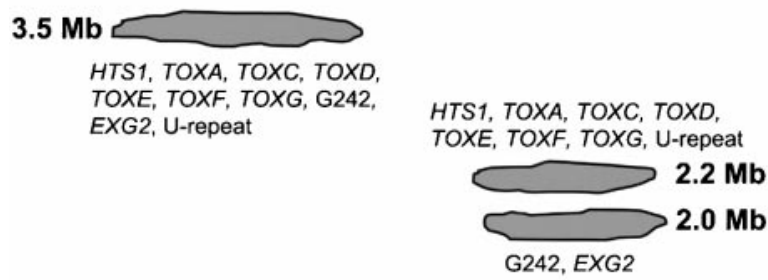

$0.7 \mathrm{Mb}$

TOXE, U-repeat

FIG. 4. Graphic summary of the distribution of known DNA sequences among the chromosomes in two types of $\mathrm{Tox2}^{+}$isolates of $\mathrm{C}$. carbonum (Ahn and Walton, 1996; Canada and D unkle, 1997). 
Type 2 (2.2 M b) TOX2 chromosomes are related to each other by a reciprocal translocation (Ahn and Walton, 1996) (Fig. 4). Additional strong support for the relatedness of these two chromosomes is the fact that they behave as homologs during meiosis (Canada and Dunkle, 1997).

With regard to whether Type 1 evolved from Type 2 or vice versa, it is significant that all of the copies of all of the TOX2 genes are on a single chromosome of $2.2 \mathrm{Mb}$ in Type 2 isolates, whereas the TOX2 genes are found on chromosomes of two sizes, 3.5 and $0.7 \mathrm{Mb}$, in Type 1 isolates. F urthermore, in Type 2 isolates no TOX2 genes and all of the DNA sequences common to $\mathrm{ToX2}^{+}$and Tox2 ${ }^{-}$isolates (i.e., G242 and EXG2) are found on a chromosome of $2.0 \mathrm{M} \mathrm{b}$, whereas in Type 1 isolates the 3.5-M b chromosome contains both TOX2 and non-TOX2 genes. Because known mechanisms of genomic rearrangements in fungi (e.g., translocation, unequal crossing over, etc.) are more likely to lead over time to greater gene dispersal rather than to greater gene linkage, Type 2 is probably ancestral to Type 1 .

A relatively recent origin for the TOX 2 genes is suggested by the fact that all natural Tox2- isolates, and other species of Cochliobolus, completely lack the genes for HC-toxin biosynthesis (Panaccione et al., 1992). Because the genes are clustered, it would have been possible for the trait of $\mathrm{HC}$-toxin biosynthesis to have moved between fungi by a process such as horizontal gene transfer of a subchromosomal fragment of D N A (Rosewich and Kistler, 2000; Walton, 2000). Based on our current knowledge, the smallest contiguous fragment of DNA that could have resulted in transfer of the trait of $\mathrm{HC}$-toxin biosynthesis is $100 \mathrm{~kb}$, which is the size of the region surrounding copy 2 of HTS1 containing at least one copy of each of the known TOX2 genes (Fig. 2). The minimum amount of DNA for complete $\mathrm{HC}$-toxin production might be larger, however, because not all of the steps of $\mathrm{HC}$-toxin biosynthesis are accounted for by the known genes; e.g., the fatty acid synthase $\beta$ subunit (the product of TOXC) requires an unknown interacting $\alpha$ subunit (Ahn and Walton, 1997). If one assumes that the TO $\times 2$ genes arrived in the genome of C. carbonum as a contiguous single-copy gene cluster, the present distribution could have arisen from a combination of gene duplication and translocation (Nikolskaya et al., 1995; Walton, 1996). Because the TO X2 genes are duplicated or triplicated in both Type 1 and Type 2 isolates (Ahn and Walton, 1996, 1997; Cheng et al., 2000), the generation of the extra copies probably occurred before the translocation. Thus, the chain of events leading to the present genomic organization of TOX2 in Type 1 isolates of C. carbonum is proposed to be horizontal transfer, duplication, and translocation.

\section{ACKNOWLEDGMENTS}

This research was supported by the U.S. D epartment of Energy D ivision of Energy Biosciences and the U.S. D epartment of Agriculture Competitive Grants Research Program.

\section{REFERENCES}

Ahn, J.-H ., and Walton, J. D . 1996. Chromosomal organization of TOX2, a complex locus required for host-selective toxin biosynthesis in $\mathrm{Co-}$ chliobolus carbonum. Plant Cell 8: 887- 897.

Ahn, J.-H ., and Walton, J. D. 1997. A fatty acid synthase gene required for production of the cyclic tetrapeptide HC-toxin, cyclo(D-Prolyl-L Alanyl-D -Alanyl-L-2-Amino-9,10-E poxi-8-0 xodecanoyl). M ol. PlantMicrobe Interact. 10: 207-214.

Ahn, J.-H ., and Walton, J. D. 1998. Regulation of cyclic peptide biosynthesis and pathogenicity in Cochliobolus carbonum by TOXE, a gene encoding a novel protein with a bZIP basic DNA binding motif and four ankyrin repeats. Mol. Gen. Genet. 260: 462- 469.

Apel, P. C., Panaccione, D. G., H olden, F. R., and Walton, J. D. 1993. Cloning and targeted gene disruption of $X Y L 1$, a $\beta$-1,4-xylanase gene from the maize pathogen Cochliobolus carbonum. $\mathrm{M}$ ol. Plant-M icrobe Interact. 6: 467- 473.

Brown, D. W., Yu, J.-H., Kelkar, H. S., Fernandes, M., Nesbitt, T. C., Keller, N. P., Adams, T. H., and Leonard, T. J. 1996. Twenty-five coregulated transcripts define a sterigmatocystin gene cluster in Aspergillus nidulans. Proc. Natl. Acad. Sci. USA 93: 1418-1422.

Canada, S. R., and Dunkle, L. D. 1997. Polymorphic chromosomes bearing the Tox2 locus in Cochliobolus carbonum behave as homologs during meiosis. Appl. Environ. Microbiol. 63: 996-1001.

Carroll, A. M., Sweigard, J. A., and Valent, B. 1994. I mproved vectors for selecting resistance to hygromycin. Fungal Genet. Newsl. 41: 22.

Cheng, Y.-Q., Ahn, J.-H ., and Walton, J. D. 1999. A putative branchedchain-amino-acid transaminase required for $\mathrm{HC}$-toxin biosynthesis and pathogenicity in Cochliobolus carbonum. Microbiology 145: 3539 3546.

Cheng, Y.-Q., and Walton, J. D. 2000. A eukaryotic alanine racemase gene involved in cyclic peptide biosynthesis. J. Biol. Chem. 275: 4096- 4911.

Covert, S. F. 1998. Supernumerary chromosomes in filamentous fungi. Curr. Genet. 33: 311-319.

Diez, B., Gutierrez, S., Barredo, J. L., van Solingen, P., van der Voort, L. H. M ., and M artin, J. F. 1990. The cluster of penicillin biosynthetic genes: I dentification and characterization of the $P c b A B$ gene encoding the $\alpha$-aminoadipyl-cysteinyl-valine synthetase and linkage to the pcbC and pcbDE genes. J. Biol. Chem. 265: 16358-16365.

Fierro, F., Barredo, J. L., Gutierrez, S., F ernandez, F. J., and M artin, J. F. 1995. The penicillin gene cluster is amplified in tandem repeats 
linked by conserved hexanucleotide sequences. Proc. Natl. Acad. Sci. USA 92: 6200-6204.

H an, Y., Liu, X., Benny, U., Kistler, H. C., and VanE tten, H. D. 2001. Genes determining pathogenicity to pea are clustered on a supernumerary chromosome in the fungal plant pathogen. Nectria haematococca. Plant J. 25: 305-314.

He, C., Rusu, A. G., Poplawski, A. M ., I rwin, J. A. G., and M anners, J. M. 1998. Transfer of a supernumerary chromosome between vegetatively incompatible biotypes of the fungus Colletotrichum gloeosporioides. Genetics 150: 1459-1466.

Keller, N. P., and H ohn, T. M . 1997. M etabolic pathway gene clusters in filamentous fungi. Fungal Genet. Biol. 21: 17-29.

Kim, H., Ahn, J.-H ., Görlach, J. M., Caprari, C., Scott-Craig, J. S., and Walton, J. D . 2001. M utational analysis of $\beta$-glucanase genes from the plant pathogenic fungus $\mathrm{C}$ ochliobolus carbonum. $\mathrm{M}$ ol. Plant- M icrobe Interact., in press.

Kimura, M., M atsumoto, G., Shingu, Y., Yoneyama, K., and Yamaguchi, I. 1998. The mystery of the trichothecene 3-0-acetyltransferase gene. FEBS L ett. 435: 163-168.

Kodama, M., Rose, M. S., Yang, G., Yun, S. H., Yoder, O. C., and Turgeon, B. G. 1999. The translocation-associated Tox1 locus of Cochliobolus heterostrophus is two genetic elements on two different chromosomes. Genetics 151: 585-586.

Kohmoto, K., and Otani, H. 1991. Host recognition by toxigenic plant pathogens. Experientia 47: 755-764.

M acC abe, A. P., Riach, M. B. R., Unkles, S. E ., and Kinghorn, J. R. 1990. The Aspergillus nidulans npeA locus consists of three contiguous genes required for penicillin biosynthesis. EMBO J. 9: 279-287.

M cCormick, S. P., Alexander, N . J., Trapp, S. E ., and H ohn, T. M. 1999. Disruption of TRI101, the gene encoding trichothecene 3-0-acetyltransferase, from Fusarium sporotrichioides. Appl. Environ. Microbiol. 65: 5252-5256.

N ikolskaya, A. N., Panaccione, D. G., and Walton, J. D. 1995. I dentification of peptide synthetase-encoding genes from filamentous fungi producing host-selective phytotoxins or analogs. Gene 165: 207-211.

Orbach, M . J., F arrall, L., Sweigard, J. A., Chumley, F. G., and Valent, B. 2000. A telomeric avirulence gene determines efficacy for the rice blast resistance gene Pi-ta. Plant Cell 12: 2019-2032.

Panaccione, D. G., Scott-Craig, J. S., Pocard, J.-A., and Walton, J. D. 1992. A cyclic peptide synthetase gene required for pathogenicity of the fungus Cochliobolus carbonum on maize. Proc. Natl. Acad. Sci. USA 89: $6590-6594$.
Pitkin, J. W., Panaccione, D. G., and Walton, J. D . 1996. A putative cyclic peptide efflux pump encoded by the TOXA gene of the plant pathogenic fungus Cochliobolus carbonum. M icrobiology 142: 1557-1565.

Pitkin, J. W., Nikolskaya, A. N., Ahn, J.-H., and Walton, J. D. 2000. Reduced virulence caused by meiotic instability of the TOX2 chromosome of Cochliobolus carbonum. Mol. Plant-Microbe Interact. 13: $80-87$.

Rohe, M ., Gierlich, A., H ermann, H ., H ahn, M ., Schmidt, B., Rosahl, S., and Knogge, W. 1995. The race-specific elicitor, NIP1, from the barley pathogen, Rhynchosporium secalis, determines avirulence on host plants of the Rrs1 resistance genotype. EM BO J. 14: 4168-4477.

Rosewich, U. L., and Kistler, H . C. 2000. Role of horizontal gene transfer in the evolution of fungi. Annu. Rev. Phytopathol. 38: 325-363.

Sambrook, J., F ritsch, E. F., and M aniatis, T. A. 1989. M olecular Cloning: A Laboratory Manual, 2nd ed. Cold Spring $\mathrm{H}$ arbor Laboratory Press, Cold Spring H arbor, NY.

Scheffer, R. P., N elson, R. R., and U llstrup, A. J. 1967. Inheritance of toxin production and pathogenicity in Cochliobolus carbonum and Cochliobolus victoriae. Phytopathology 57: 1288-1291.

Scott-Craig, J. S., Panaccione, D. G., Cervone, F., and Walton, J. D. 1990. Endopolygalacturonase is not required for pathogenicity of Cochliobolus carbonum on maize. Plant Cell 2: 1191-1200.

Tanaka, A., and Tsuge, T. 2000. Structural and functional complexity of the genomic region controlling AK-toxin biosynthesis and pathogenicity in the Japanese pear pathotype of Alternaria alternata. M ol. PlantM icrobe Interact. 13: 975-986.

Tzeng, T. H ., Lyngholm, L. K., F ord, C. F., and Bronson, C. R. 1992. A restriction fragment length polymorphism map and electrophoretic karyotype of the fungal maize pathogen Cochliobolus heterostrophus. Genetics 130: 81-96.

van Kan, J. A., van den Ackerveken, G. F., and de Wit, P. J. 1991. Cloning and characterization of CDNA of avirulence gene avr9 of the fungal pathogen Cladosporium fulvum, causal agent of tomato leaf mold. $\mathrm{M} \mathrm{ol}$. Plant-M icrobe Interact. 4: 52-59.

Walton, J. D. 1996. H ost-selective toxins: Agents of compatibility. Plant Cell 8: 1723-1733.

Walton, J. D. 2000. Horizontal gene transfer and the evolution of secondary metabolite gene clusters in fungi: An hypothesis. F ungal $\mathrm{G}$ enet. Biol. 30: 167-171.

Woloshuk, C. P., and Prieto, R. 1998. Genetic organization and function of the aflatoxin B1 biosynthetic genes. FEMS Microbiol. Lett. 160: $169-176$. 